\title{
High strain rate response of UHP(FR)C in compression
}

\author{
Anatoly Bragov ${ }^{1}$, Alexandr Konstantinov ${ }^{1}$, Andrey Lomunov ${ }^{1}$, Daniele Forni ${ }^{2,3}$, Gianmario Riganti ${ }^{3}$, and Ezio Cadoni ${ }^{3}$ a \\ ${ }^{1}$ Research Institute of Mechanics, Lobachevsky State University of Nizhny Novgorod, Nizhny Novgorod, Russia \\ ${ }^{2}$ Department of Structural, Geotechnical and Building Engineering, Politecnico di Torino, 10129 Torino, Italy \\ ${ }^{3}$ DynaMat Laboratory, University of Applied Sciences of Southern Switzerland, 6952 Canobbio, Switzerland
}

\begin{abstract}
The objective of this study was to investigate the compression behaviour of the UHPFRC and its matrix (UHPC) under high strain rate. Two experimental set-ups were used for compression testing: a traditional Split Hopkinson Pressure Bars and a compression version of the Modified Hopkinson Bar. The tests were conducted, in the range of 100-500 s ${ }^{-1}$ on cylindrical specimens with both diameter and height of $20 \mathrm{~mm}$. Results show significant increases in peak strength and dissipated energy.
\end{abstract}

\section{Introduction}

Nowadays Ultra-High Performance (Fibre-Reinforced) Concretes - UHP(FR)Cs are principally used for rehabilitation and strengthening of structures. While many authors have examined the quasi-static behaviour (for example [1-6]), there is still a lack of knowledge about the material behaviour of UHP(FR)C under high strain rates above $100 \mathrm{~s}^{-1}$. Recently, a few works about the tensile behaviour have been published as [7-11].

The objective of this study was to investigate the compression behaviour of the UHPFRC and its matrix under high strain rate. Two experimental set-ups were used for compression testing: a traditional Split Hopkinson Pressure Bars [12] and a compression version of the Modified Hopkinson Bar. The tests were conducted in the range of $100-600 \mathrm{~s}^{-1}$ on cylindrical specimens with both diameter and height of $20 \mathrm{~mm}$.

\section{Materials}

The materials here analysed were commercial products characterized by high strength and durability, thanks to the exceptional properties of the matrix (UHPC). UHPFRC was obtained adding to the UHPC an elevate percentage of high strength steel fibres reinforcement ( $3 \%$ in volume) having a diameter of $0.16 \mathrm{~mm}$ and a length of $13 \mathrm{~mm}$. The UHP(FR)C specimens had a cylindrical shape with diameter and height of $20 \mathrm{~mm}$. All specimens were drilled out from standard cube $(150 \mathrm{~mm}$ side $)$. The results of the quasi-static compressive tests were $\mathrm{f}_{C}=104 \pm 22 \mathrm{MPa}$ for UHPC and $\mathrm{f}_{C}=127 \pm 21 \mathrm{MPa}$ for UHPFRC.

The Young's modulus was $51 \mathrm{GPa}$. Moreover UHPFRC had high durability guaranteed by high water and low gas permeability, very high resistance to chloride penetration, carbonation, acid attack and abrasion.

\footnotetext{
${ }^{a}$ Corresponding author: ezio.cadoni@supsi.ch
}

\section{Experimental set-ups}

The high strain rate compressive behaviour was examined by means of two set-ups.

\subsection{Split Hopkinson Pressure Bar}

The dynamic compression tests were performed using a Split Hopkinson Pressure Bar (SHPB), installed at the Dynamic Testing of Materials Laboratory of the Research Institute of Mechanics - Lobachevsky State University of Nizhny Novgorod (Russia), which consists of an input (2) and an output (5) bars with the specimen (4) sandwiched between them as schematically shown in Fig. 1. When the strike bar (1) impacts onto the input bar a compressive incident wave $\varepsilon_{\mathrm{I}}(\mathrm{t})$ travels along the input bar. Once it reaches the specimen, a reflected wave $\varepsilon_{\mathrm{R}}(\mathrm{t})$ and a transmitted wave $\varepsilon_{\mathrm{T}}(\mathrm{t})$ are generated, propagating along the input and output bar respectively. According to the onedimension wave propagation theory the forces and particle velocities/displacements at the two faces of specimen can be determined by those three waves recorded. In Fig. 1a is also shown the Lagrangian graph describing the strain history of the two bars.

In Fig. 2 the incident, reflected and transmitted pulses measured on input and output bars in a dynamic compression test of UHPC specimen are shown. It can be observed as at high strain rate the specimen failure is reached just in the first cycle of loading. The time necessary to bring the specimen at failure in compression is about $100 \mu \mathrm{s}$.

With this set-up were carried out the test with higher strain rates.

\subsection{Modified Hopkinson Bar in Compression}

The Modified Hopkinson Bar for compression test installed at the DynaMat Laboratory (Fig. 3) consists of a hydraulic actuator (1) that put in tension a pre-stressed loading bar (2) thanks to a blocking ring (3) placed at the other extremity of this bar (see Fig. 4a). The pre-stressed

This is an Open Access article distributed under the terms of the Creative Commons Attribution License 4.0, which permits unrestricted use, distribution, and reproduction in any medium, provided the original work is properly cited. 

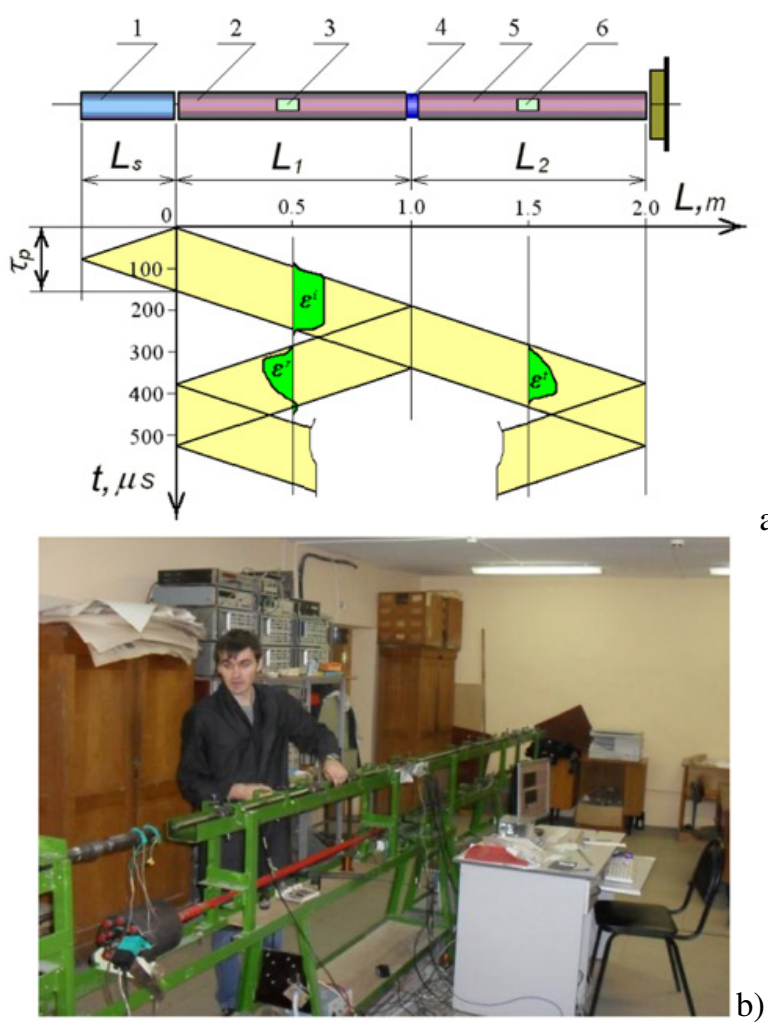

Figure 1. Dynamic compression testing set-up: a) scheme and Lagrangian graph; b) view.

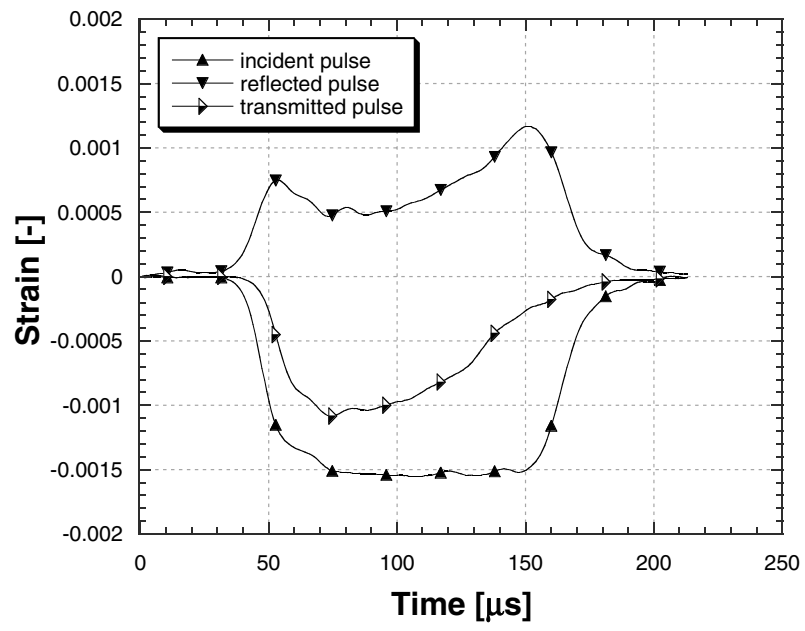

Figure 2. Signals measured on the input and output of UHPC.

bar was a high strength steel bar having a diameter of $12 \mathrm{~mm}$ and a length of $6 \mathrm{~m}$. This pre-stressed bar is directly connected to an aluminium bar with a diameter of $30 \mathrm{~mm}$ and a length of $3 \mathrm{~m}$ working as input bar (4). The specimen (5) was sandwiched between the input bar and another identical bar used as output bar (6). Pulling the pre-stressed bar it is possible to drive the test by the energy stored in it. The test starts when a fragile bolt (see Fig. 4b) positioned between the pre-stressed bar and the hydraulic actuator (1) by suddenly breaks. Consequently a rectangular stress wave pulse is generated and propagates through the input bar, the specimen (5) and the output bar (6), causing a

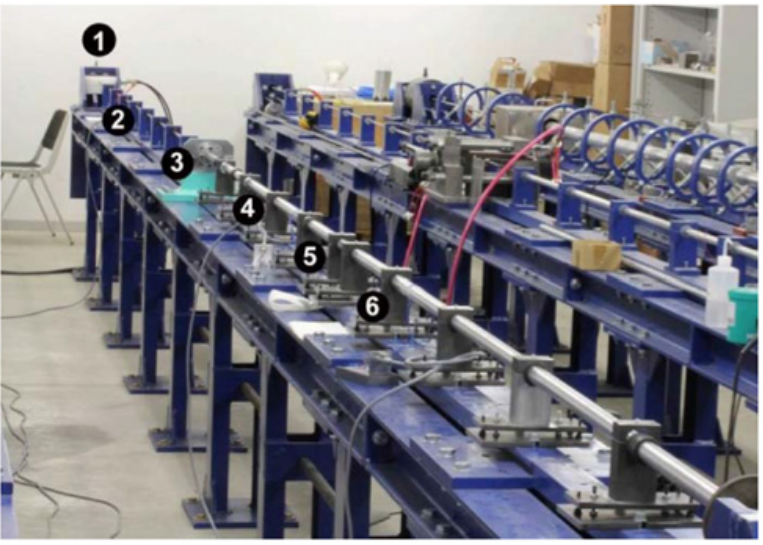

Figure 3. Modified Hokinson Bar set-up in compression.

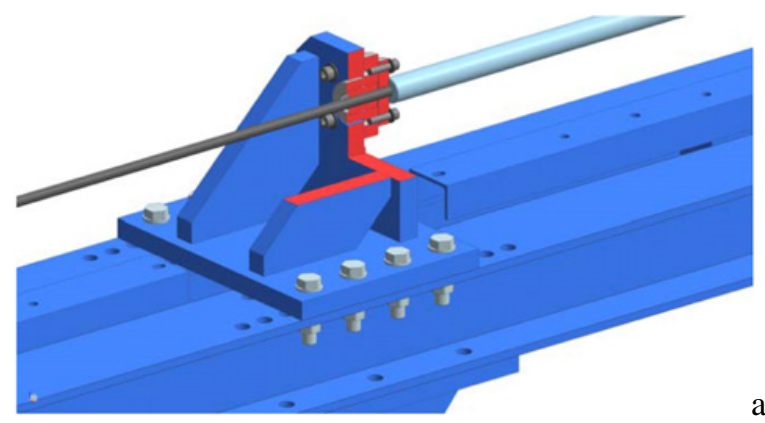

a)

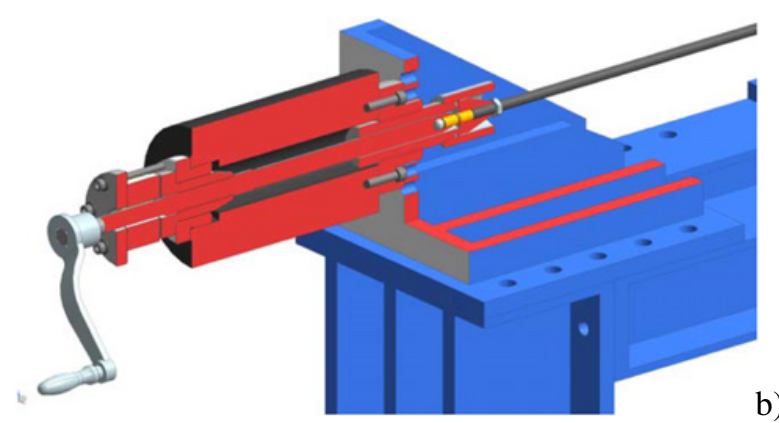

b)

Figure 4. Details of the MHB in compression: a) blocking ring; b) fragile bolt.

state of compression stress in the specimen. By the strain gauges placed on the input and output bars the test signals were obtained and in Fig. 5 the input and output signals (Fig. 5a) as well as the incident, reflected and transmitted signals (Fig. 5b) are shown.

\section{Results}

The tests performed by means of SHPB were carried out using two (aluminium and steel) strikers having a diameter of $20 \mathrm{~mm}$ and a length of $300 \mathrm{~mm}$. To obtain the strain rates three different pressure values were used (1, 3 and 6 bars). In the MHB only one velocity were used in order to compare the UHPFRC and UHPC (the preload was $50 \mathrm{kN}$ ). 

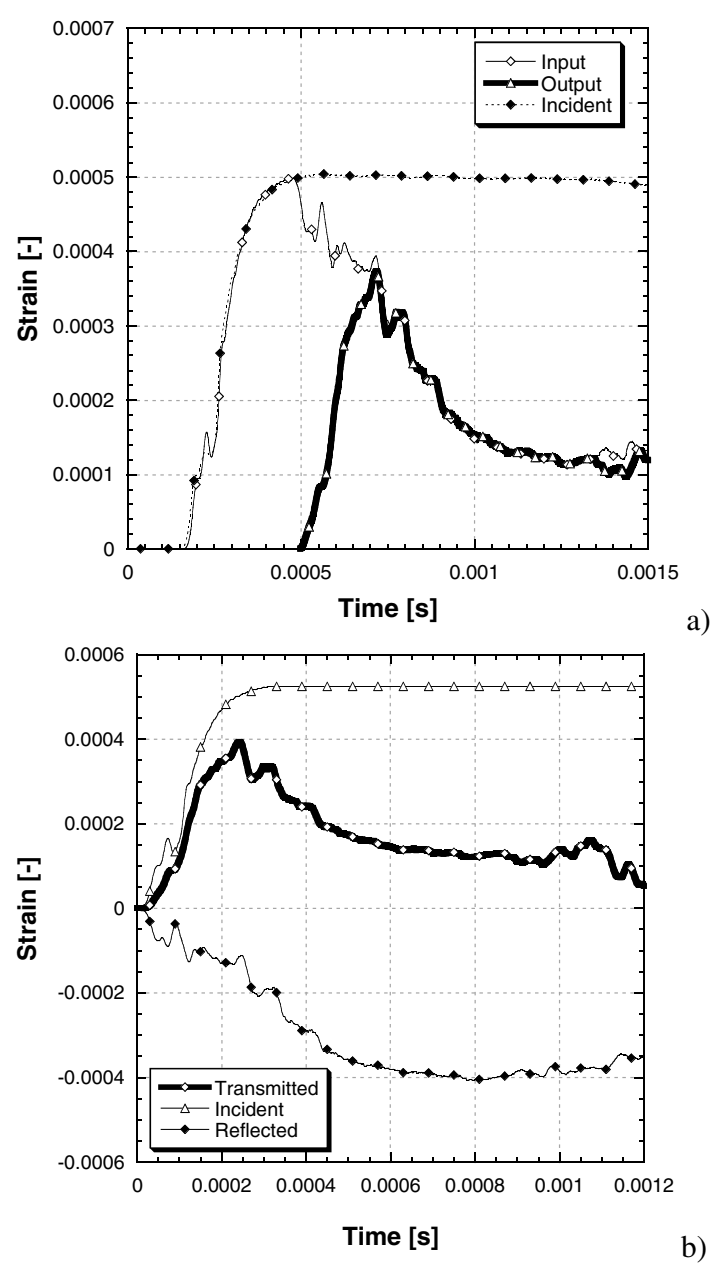

b)

Figure 5. Compression test: a) input and output signals; b) incident, reflected and transmitted signals.

\subsection{Ultra High Performance Concrete}

\subsubsection{SHPB results}

The tests on UHPC specimen were performed using the aluminium striker at 1 and 3 bars as pressure in the gas gun obtaining an impact velocity equal to 15.4 and $27.2 \mathrm{~m} / \mathrm{s}$ respectively. The strain rate obtained was in average 181 and $462 \mathrm{~s}^{-1}$. As well known also in this case it can be observed as the compressive strength increases with increasing strain rate.

In Tables 1 and 2 are collected the results at the two strain rates while in Figs. 6 and 7 the stress versus time curves are shown.

\subsubsection{MHB results}

The compression test using the MHB was performed imposing a $50 \mathrm{kN}$ of preload that produce an equivalent impact of $11.3 \mathrm{~m} / \mathrm{s}$. In Table 3 and Fig. 8 the results are shown.
Table 1. Results on UHPC_pressure 1 bar. $v_{\text {impact }}=15.44 \mathrm{~m} / \mathrm{s}$.

\begin{tabular}{|l|c|c|c|c|c|c|}
\hline Specimen & $\begin{array}{c}\text { Stress } \\
\text { Rate } \\
{[\mathbf{G P a} / \mathbf{s}]}\end{array}$ & $\begin{array}{c}\text { Max } \\
\text { Stress } \\
{[\mathbf{M P a}]}\end{array}$ & $\begin{array}{c}\text { Fract. } \\
\text { strain } \\
{[\% \mathbf{\%}]}\end{array}$ & $\begin{array}{c}\text { Fract. } \\
\text { time } \\
\boldsymbol{\mu} \mathbf{s}]\end{array}$ & $\begin{array}{c}\text { Strain } \\
\text { rate } \\
{\left[\mathbf{s}^{-\mathbf{1}}\right]}\end{array}$ & $\begin{array}{c}\text { Total } \\
\mathbf{e n e r g y} \\
{\left[\mathbf{k J} / \mathbf{m}^{\mathbf{2}}\right]}\end{array}$ \\
\hline UHPC_29 & $5^{\prime} 311$ & 96.22 & 9 & 65 & 200 & 37.51 \\
\hline UHPC_30 & $5^{\prime} 509$ & 100.28 & 11 & 62 & 214 & 39.13 \\
\hline UHPC_31 & $5^{\prime} 995$ & 91.22 & 5 & 40 & 148 & 27.08 \\
\hline UHPC_34 & $6^{\prime} 820$ & 105.95 & 6 & 40 & 160 & 29.57 \\
\hline Average & $5^{\prime} 909$ & 98.42 & 7.97 & 52 & 181 & 33.32 \\
& $(672)$ & $(6.24)$ & $(2.84)$ & $(14)$ & $(32)$ & $(5.89)$ \\
\hline
\end{tabular}

Table 2. Results on UHPC_pressure 3 bar. vimpact $=27.2 \mathrm{~m} / \mathrm{s}$.

\begin{tabular}{|l|c|c|c|c|c|c|}
\hline Specimen & $\begin{array}{c}\text { Stress } \\
\text { Rate } \\
{[\mathbf{G P a} / \mathbf{s}]}\end{array}$ & $\begin{array}{c}\text { Max } \\
\text { Stress } \\
{[\mathbf{M P a}]}\end{array}$ & $\begin{array}{c}\text { Fract. } \\
\text { strain } \\
{[\% \mathbf{c}]}\end{array}$ & $\begin{array}{c}\text { Fract. } \\
\text { time } \\
\boldsymbol{\mu} \mathbf{s}]\end{array}$ & $\begin{array}{c}\text { Strain } \\
\mathbf{r a t e} \\
{\left[\mathbf{s}^{-\mathbf{1}}\right]}\end{array}$ & $\begin{array}{c}\text { Total } \\
\mathbf{e n e r g y} \\
{\left[\mathbf{k J} / \mathbf{m}^{\mathbf{2}}\right]}\end{array}$ \\
\hline UHPC_35 & $12^{\prime} 990$ & 167.6 & 6.28 & 24 & 465 & 65.21 \\
\hline UHPC_36 & $9^{\prime} 364$ & 126.7 & 7.83 & 23 & 588 & 67.17 \\
\hline UHPC_37 & $14^{\prime} 783$ & 197.9 & 6.17 & 22 & 409 & 73.33 \\
\hline UHPC_38 & $17^{\prime} 010$ & 198.7 & 6.16 & 19 & 385 & 63.32 \\
\hline Average & $13{ }^{\prime} 537$ & 172.7 & 6.61 & 22 & 462 & 67.26 \\
& $\left(3^{\prime} 232\right)$ & $(33.9)$ & $(0.81)$ & $(2)$ & $(91)$ & $(4.34)$ \\
\hline
\end{tabular}

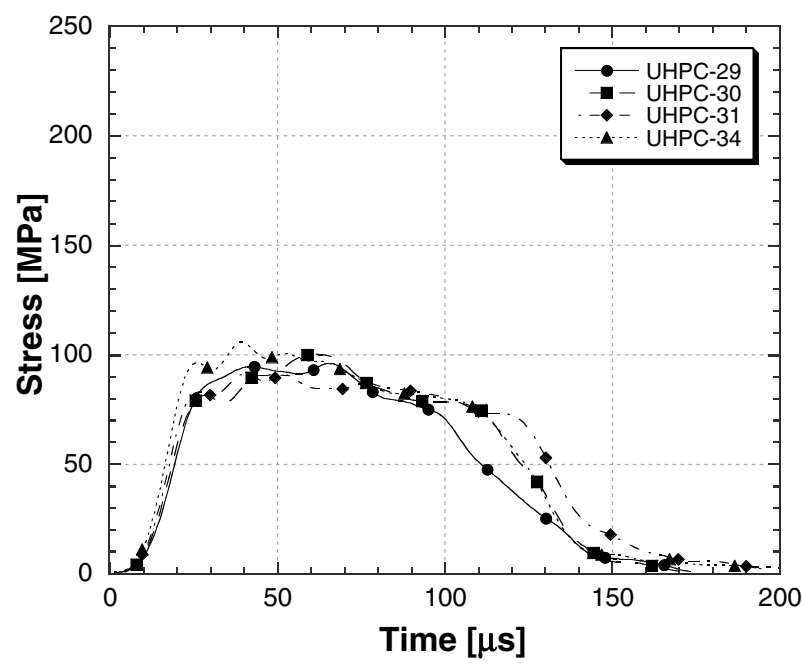

Figure 6. Results on UHPC at $181 \mathrm{~s}^{-1}$.

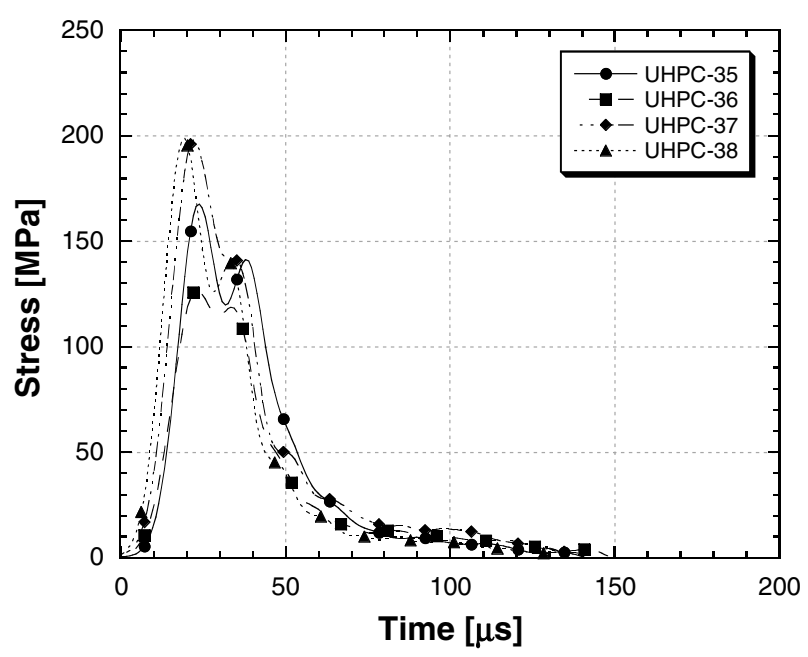

Figure 7. Results on UHPC at $462 \mathrm{~s}^{-1}$. 


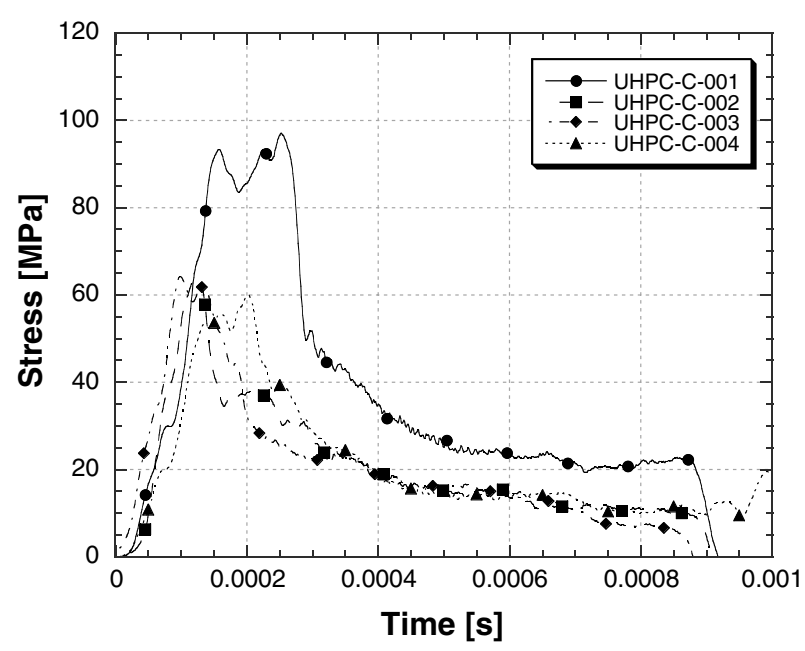

Figure 8. Results on UHPC at $136 \mathrm{~s}^{-1}$.

Table 3. Results on UHPC with MHB.

\begin{tabular}{|l|c|c|c|c|c|c|}
\hline Specimen & $\begin{array}{c}\text { Stress } \\
\text { Rate } \\
{[\mathbf{G P a} / \mathbf{s}]}\end{array}$ & $\begin{array}{c}\text { Stress } \\
{[\mathbf{M P a}]}\end{array}$ & $\begin{array}{c}\text { Fract. } \\
\mathbf{s t r a i n} \\
{[\% \mathbf{c}]}\end{array}$ & $\begin{array}{c}\text { Fract. } \\
\text { time } \\
\boldsymbol{\mu} \mathbf{s}]\end{array}$ & $\begin{array}{c}\text { Strain } \\
\mathbf{r a t e} \\
{\left[\mathbf{s}^{-\mathbf{1}}\right]}\end{array}$ & $\begin{array}{c}\text { Tot. } \\
\mathbf{e n e r g y} \\
{\left[\mathbf{k J J}_{\mathbf{m}} \mathbf{2}^{\mathbf{2}}\right]}\end{array}$ \\
\hline UHPC_01 & 1176 & 97.06 & 22.19 & 252 & 141 & 133.7 \\
\hline UHPC_02 & 934 & 64.1 & 8.51 & 121 & 153 & 61.65 \\
\hline UHPC_03 & 722 & 64.23 & 5.58 & 98 & 113 & 54.94 \\
\hline UHPC_04 & 340 & 60.15 & 13.18 & 201 & 137 & 70.87 \\
\hline Average & 793 & 71.39 & 12.37 & 168 & 136 & 80.30 \\
& $(354)$ & $(17.22)$ & $(7.26)$ & $(71)$ & $(17)$ & $(36.22)$ \\
\hline
\end{tabular}

Table 4. Results on UHPFRC_pressure 3 bar. $v_{\text {impact }}=27.2 \mathrm{~m} / \mathrm{s}$.

\begin{tabular}{|c|c|c|c|c|c|c|}
\hline Specimen & $\begin{array}{c}\text { Stress } \\
\text { Rate } \\
{[\mathrm{GPa} / \mathrm{s}]}\end{array}$ & $\begin{array}{c}\text { Max } \\
\text { Stress } \\
{[\text { MPa] }}\end{array}$ & $\begin{array}{c}\text { Fract. } \\
\text { strain } \\
{[\% o]}\end{array}$ & $\begin{array}{c}\text { Fract. } \\
\text { time } \\
\mu \mathrm{s}]\end{array}$ & $\begin{array}{c}\text { Strain } \\
\text { rate } \\
{\left[\mathrm{s}^{-1}\right]}\end{array}$ & $\begin{array}{c}\text { Tot. } \\
\text { energy } \\
{\left[\mathrm{kJ} / \mathrm{m}^{2}\right]}\end{array}$ \\
\hline UHPFRC_37 & 13,676 & 179.64 & 6.82 & 23 & 428 & 101.33 \\
\hline UHPFRC_38 & $14 ' 463$ & 183.45 & 13.04 & 36 & 392 & 117.17 \\
\hline UHPFRC_39 & $13 ' 811$ & 179.29 & 7.27 & 22 & 460 & 107.11 \\
\hline UHPFRC_40 & $11 ’ 258$ & 153.96 & 16.89 & 36 & 585 & 119.65 \\
\hline Average & $\begin{array}{l}13^{\prime} 302 \\
(1 ' 405)\end{array}$ & $\begin{array}{l}174.09 \\
(13.55)\end{array}$ & $\begin{array}{l}11.00 \\
(4.84)\end{array}$ & $\begin{array}{l}29 \\
(8)\end{array}$ & $\begin{array}{l}466 \\
(84)\end{array}$ & $\begin{array}{r}111.32 \\
(8.58)\end{array}$ \\
\hline
\end{tabular}

\subsection{Ultra High Performance Fibre Reinforced Concrete}

\subsubsection{SHPB results}

For the tests on UHPFRC the pressure in the gas gun was incremented at 3 and 6 bars so impact velocities equal to $27.2 \mathrm{~m} / \mathrm{s}$ (for aluminium striker) and $20.8 \mathrm{~m} / \mathrm{s}$ (for steel striker) were obtained. The resulting strain rates were respectively. 466 and $688 \mathrm{~s}^{-1}$.

The results on UHPFRC are resumed in Tables 4 and 5 and in Figs. 9 and 10.

\subsubsection{MHB results}

The tests performed by means of MHB had exactly the same condition used for UHPC.

The strain rate obtained was in average equal to $111 \mathrm{~s}^{-1}$.
Table 5. Results on UHPFRC_pressure 3 bar. $\mathrm{v}_{\text {impact }}=20.8 \mathrm{~m} / \mathrm{s}$.

\begin{tabular}{|c|c|c|c|c|c|c|}
\hline Spec & $\begin{array}{c}\text { Stress } \\
\text { Rate } \\
{[\mathrm{GPa} / \mathrm{s}]}\end{array}$ & \begin{tabular}{|c} 
Max \\
Stress \\
{$[\mathrm{MPa}]$}
\end{tabular} & $\begin{array}{c}\text { Fract. } \\
\text { strain } \\
{[\%]}\end{array}$ & $\begin{array}{c}\begin{array}{c}\text { Fract. } \\
\text { time } \\
\mu \mathrm{s}]\end{array} \\
\end{array}$ & $\begin{array}{c}\text { Strain } \\
\text { rate } \\
{\left[\mathrm{s}^{-1}\right]}\end{array}$ & \begin{tabular}{|c|} 
Tot. \\
energy \\
{$\left[\mathrm{kJ} / \mathrm{m}^{2}\right]$}
\end{tabular} \\
\hline UHPFRC_44 & $15^{\prime} 622$ & \begin{tabular}{|l|}
178.74 \\
\end{tabular} & 10.53 & 21 & 754 & 108.51 \\
\hline UHPFRC_45 & $15^{\prime} 589$ & 176.10 & 8.83 & 19 & 777 & 107.38 \\
\hline UHPFRC_46 & $19^{\prime} 445$ & 249.85 & 8.45 & 22 & 537 & 81.91 \\
\hline UHPFRC_47 & 19'641 & 229.10 & 9.83 & 21 & 684 & 95.64 \\
\hline Average & \begin{tabular}{|l|l}
$17 ' 574$ \\
$(2 ' 275)$
\end{tabular} & $\begin{array}{l}208.45 \\
(36.83)\end{array}$ & $\begin{array}{c}9.41 \\
(0.94)\end{array}$ & $\begin{array}{l}21 \\
\text { (1) }\end{array}$ & $\begin{array}{c}688 \\
(108)\end{array}$ & $\begin{array}{c}98.36 \\
(12.41)\end{array}$ \\
\hline
\end{tabular}

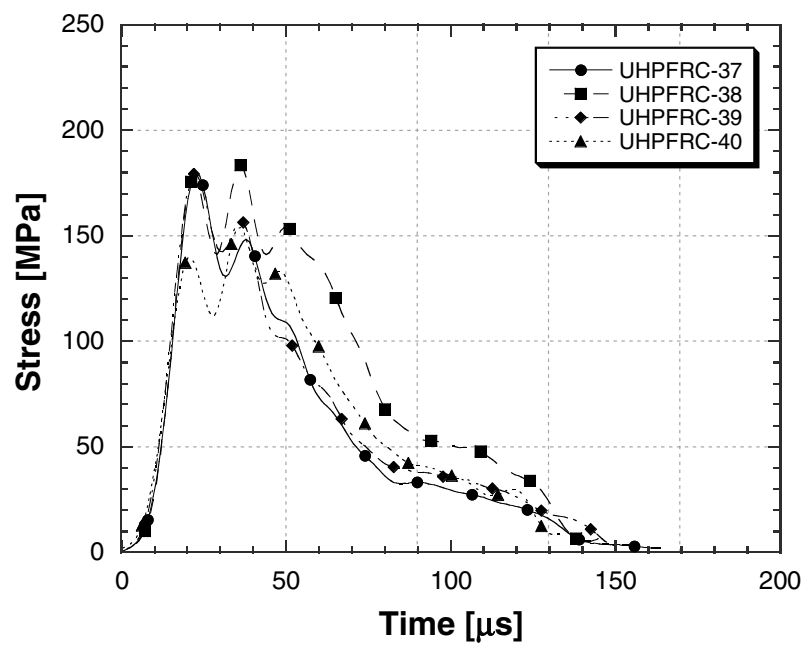

Figure 9. Results on UHPFRC at $466 \mathrm{~s}^{-1}$.

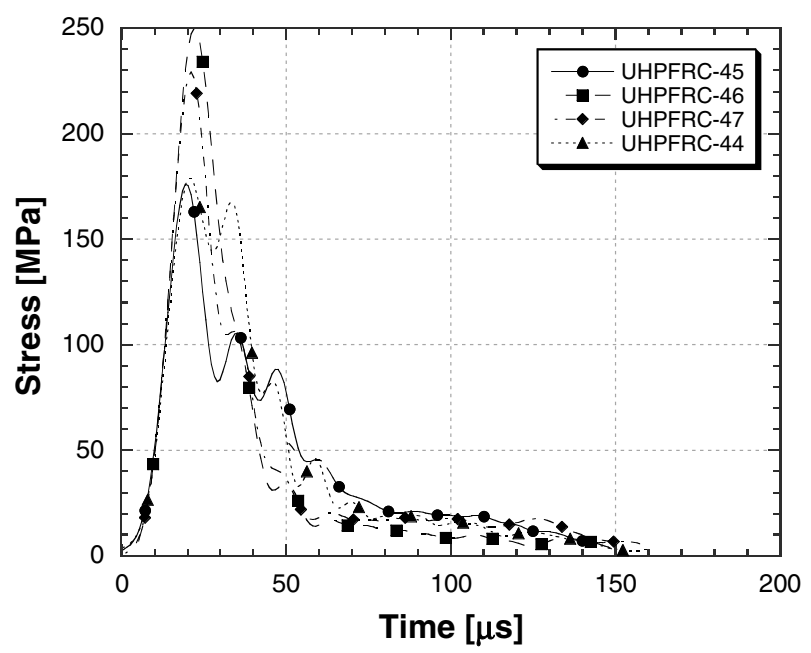

Figure 10. Results on UHPFRC at $688 \mathrm{~s}^{-1}$.

\section{Discussion}

UHPC is a brittle material while UHPFRC can reduce the brittleness thanks to the addition of fibers in the mix. In particular the presence of the fibres enhances the post-peak behaviour. In Figs. 12 and 13 the stress versus displacement curves of UHPC and UHPFRC specimens tested in tension at about 450 and $700 \mathrm{~s}^{-1}$ are shown.

From these results it can be easily recognized the fibres role in the post-peak behaviour. The energy dissipation capacity is enhanced because of higher stress level for the same strain level. The peak strength seems not be 
Table 6. Results on UHPFRC with MHB.

\begin{tabular}{|l|c|c|c|c|c|c|}
\hline Specimen & $\begin{array}{c}\text { Stress } \\
\text { Rate } \\
{[\mathbf{G P a} / \mathbf{s}]}\end{array}$ & $\begin{array}{c}\text { Max } \\
\text { Stress } \\
{[\mathbf{M P a}]}\end{array}$ & $\begin{array}{c}\text { Fract. } \\
\text { strain } \\
{[\%]}\end{array}$ & $\begin{array}{c}\text { Fract. } \\
\text { time } \\
\mu \mathbf{s}]\end{array}$ & $\begin{array}{c}\text { Strain } \\
\text { rate } \\
{\left[\mathbf{s}^{-\mathbf{1}}\right]}\end{array}$ & $\begin{array}{c}\text { Tot. } \\
\mathbf{e n e r g y} \\
{\left[\mathbf{k J} / \mathbf{m}^{\mathbf{2}}\right]}\end{array}$ \\
\hline UHPFRC_002 & 677 & 100.5 & 16 & 279 & 78 & 93.70 \\
\hline UHPFRC_003 & 955 & 92.53 & 12 & 211 & 108 & 113.19 \\
\hline UHPFRC_004 & 716 & 88.92 & 24 & 255 & 135 & 109.70 \\
\hline UHPFRC_005 & 859 & 91.68 & 17 & 266 & 124 & 107.57 \\
\hline Average & 802 & 93.41 & 17 & 255 & 111 & 106.06 \\
& $(127)$ & $(4.9)$ & $(5)$ & $(29)$ & $(25)$ & $(8.5)$ \\
\hline
\end{tabular}

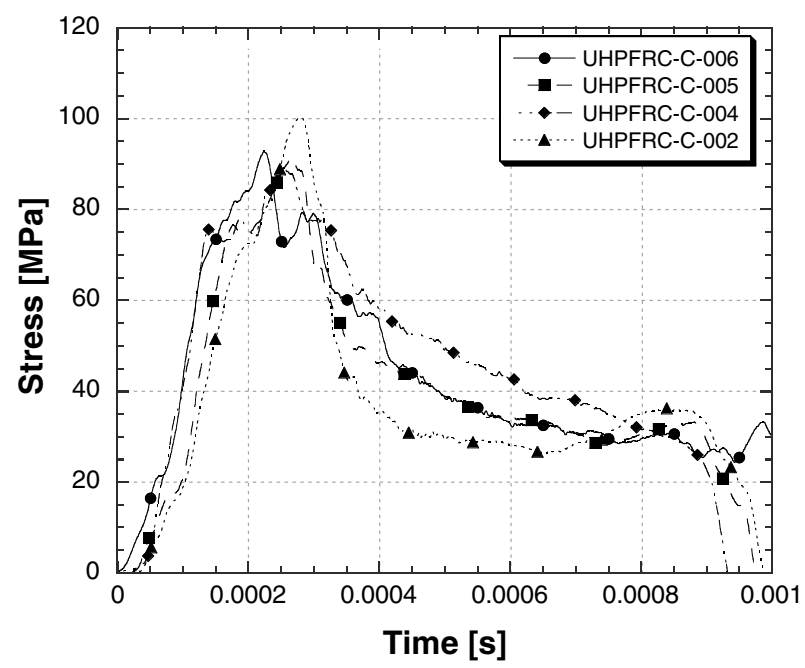

Figure 11. Results on UHPFRC at $110 \mathrm{~s}^{-1}$.

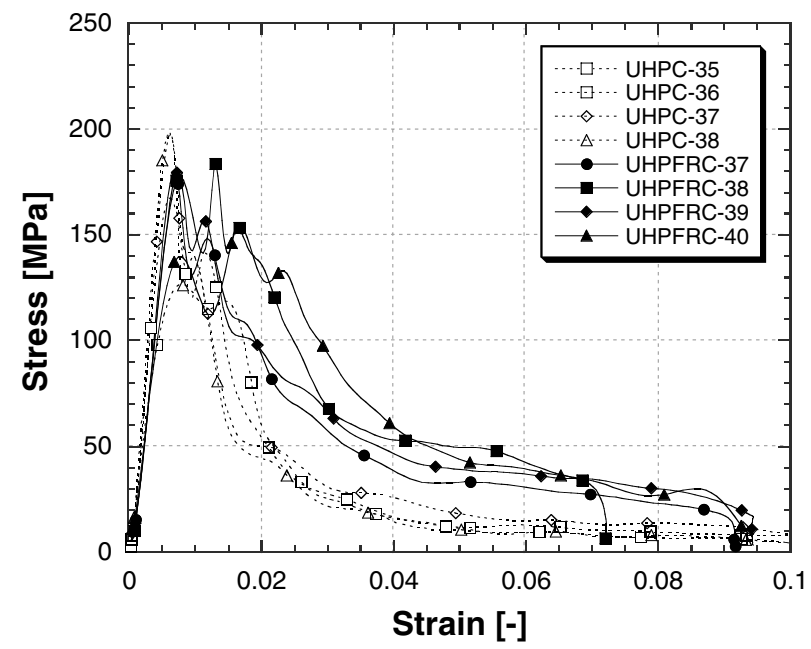

Figure 12. Comparison between UHPFRC and UHPC response at $466 \mathrm{~s}^{-1}$.

influenced by the fibres presence. This can be reasonable because the principal role of the fibres is strictly related to the bridging effect.

The evolution of the strength in function of the stress rate (measured as the slope of the stress versus time curve) is shown in Fig. 14. The scattering of the results can be ascribed to several motivations. Firstly, the boundary

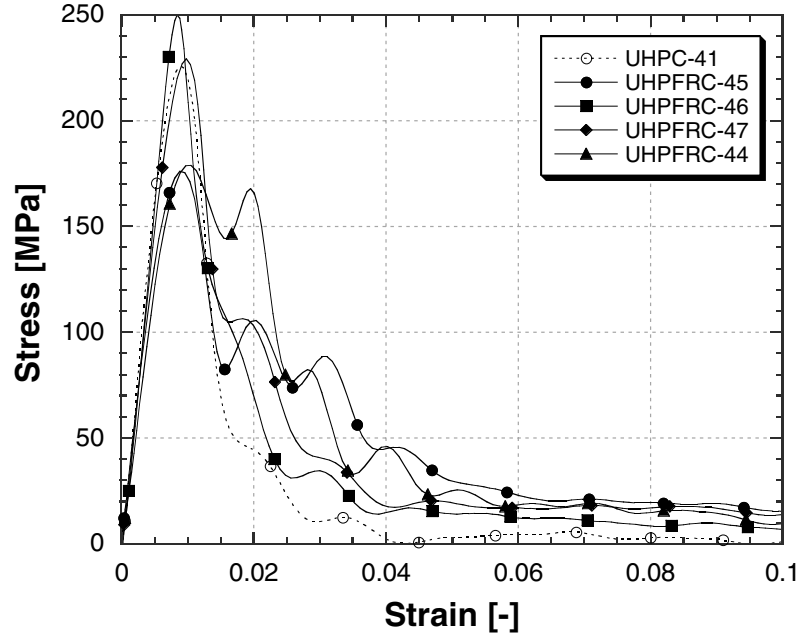

Figure 13. Comparison between UHPFRC and UHPC response at $688 \mathrm{~s}^{-1}$.

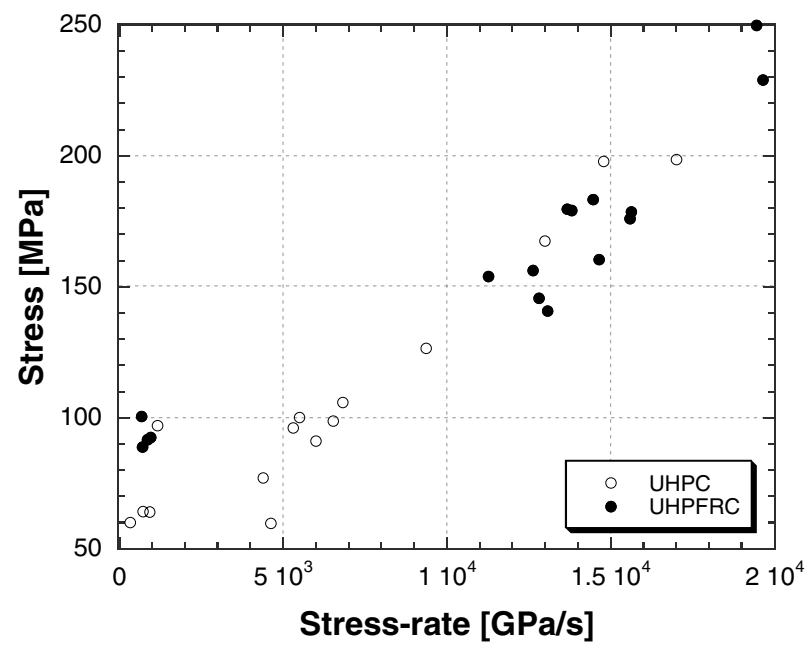

Figure 14. Strength versus stress-rate of UHPC and UHPFRC.

conditions of the specimens such as flatness, presence of grease or copper gasket. Secondly, the presence of the fibres can be considered a discontinuity in the materials causing the premature failure. Finally, the grade of dispersion of the fibres in the cross section is definitely different in each specimen.

\section{Concluding remarks}

The results of dynamic experimental investigations on ultra-high performance fibre reinforced concrete in compression have been described. The experiments were carried out using a Split Hopkinson Pressure Bar and a modified Hopkinson bar device.

UHPFRC shows an increase of the mechanical features as post-peak strength, failure time, and absorption energy respect to UHPC. The reason for this increase in the performance can be related to the contribution of the fibres distribution. 
The results obtained at high strain rates are the basis to interpret the results acquired during blast experiments and to assess the goodness of the modelling.

The authors are grateful to Matteo Dotta and Nicoletta Tesio for their help with the test experiments. This research activity was partially financial supported by the Scientific \& Technological Cooperation Programme Switzerland-Russia in the frame of Utilisation of Specific Infrastructure Project called "Construction materials under high strain rate". Swiss part of investigation was financed by armasuisse-Science and Technology of the Swiss Federal Department of Defence. Civil Protection and Sport (Grant 8003417679). Russian part of investigation was financed by the Russian Science Foundation (Grant 14-19-01096).

\section{References}

[1] A.E. Naaman, H.W. Reinhardt, Mat. Struct., 39, 547 (2006).

[2] K. Habel, M. Viviani, E. Denarié, E. Brühwiler, Cem. Conc. Res. 36, 1362 (2006).
[3] S.L. Yang, S.G. Millard, M.N. Soutsos, S.J. Barnett, T.T. Le, Constr. Build. Mater. 23, 2291(2009).

[4] H. Katrin, G. Paul, Cem. Concr. Compos. 30, 938 (2008).

[5] Z. Rong, W. Sun, Y. Zhang, Int. J. Impact Eng. 37, 515 (2010).

[6] R. Yu, P. Spiesz, H.J.H. Brouwers, Const. Build. Mat. 68, 158 (2014).

[7] S.H. Park, Kim D.J, Ryu G.S., Koh K.T., Cem. Concr. Compos. 34, 172-84 (2012).

[8] E. Cadoni, A.M. Bragov, A. Caverzan, M. di Prisco, A. Konstantinov, A. Lomunov, Engng. Trans. 58(3-4), 9 (2011).

[9] A. Caverzan, E. Cadoni, M. di Prisco, Mech. Mat. 59, 87 (2013).

[10] A. Caverzan, E. Cadoni, M. di Prisco, Int. J. Impact Engng 45, 28 (2012).

[11] E. Cadoni, D. Forni, EPJ-ST (to be published) (2015).

[12] A.M. Bragov, Y. Petrov, B.L. Karihaloo, A. Konstantinov, D.A. Lamzin, A.K. Lomunov, I.V. Smirnov, Eng. Fract. Mech. 110, 477 (2013). 